\title{
A review on the polymer properties of Hydrophilic, partially Degradable and Bioactive acrylic Cements (HDBC)
}

\author{
Luciano F. Boesel ${ }^{\mathrm{a}, *}$, Rui L. Reis ${ }^{\mathrm{a}, \mathrm{b}}$ \\ a3B's Research Group_Biomaterials, Biodegradables and Biomimetics, Department of Polymer Engineering, \\ University of Minho, Campus of Gualtar, 4710-057 Braga, Portugal \\ ${ }^{\mathrm{b}}$ IBB - Institute for Biotechnology and Bioengineering, PT Government Associated Laboratory, Braga, Portugal
}

Received 17 July 2007; received in revised form 13 September 2007; accepted 13 September 2007

Available online 25 September 2007

\begin{abstract}
Acrylic bone cements were developed around 50 years ago for the fixation of hip prostheses during arthroplasty. Over the intervening years, a series of drawbacks have been disclosed that have fostered intensive research on the development of novel or alternative formulations to the standard acrylic cements. Here, we will review the development and characterization of a novel class of cements, the Hydrophilic, partially Degradable and Bioactive Cements (HDBCs), an example of multifunctional cements. They were developed to have improved biocompatibility and initial fixation to the prosthesis and to induce the growth of bone on the surface of the cement and within pores generated by the degradation of the solid component. HDBCs have higher water uptake than typical acrylic cements, leading to press-fitting inside constrained cavities. They are tougher, albeit less stiff and strong than hydrophobic cements, and their mechanical properties may be easily adjusted by small changes in composition. Last, the simultaneous bioactive and degradable character of HDBCs have been shown to allow in vitro growth of calcium phosphates into pores within the bulk of the cement.
\end{abstract}

(C) 2007 Elsevier Ltd. All rights reserved.

Keywords: Bioactive; Mechanical properties; Degradable; Swelling pressure; Hydrophilic

\section{Contents}

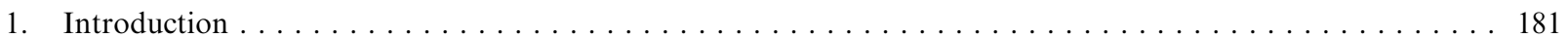

2. Composition and curing parameters of Hydrophilic, partially Degradable and Bioactive Cements (HDBCs) . 182

3. Water uptake and press-fitting effect in confined environments $\ldots \ldots \ldots \ldots \ldots \ldots \ldots \ldots \ldots \ldots \ldots$

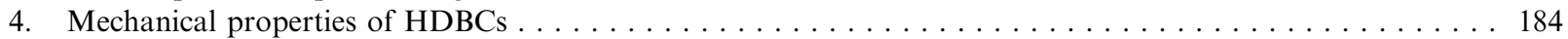

\footnotetext{
Abbreviations: AA, acrylic acid; BPO, benzoyl peroxide; DMT, dimethyl-p-toluidine; d $V$, swelling, expressed as change in volume; $E_{\mathrm{c}}$, compressive modulus; $E_{\mathrm{t}}$, tensile modulus; HA, hydroxyapatite; $\operatorname{HDBC(s),~hydrophilic,~partially~degradable~and~bioactive~cement(s);~}$ HEMA, 2-hydroxyethyl methacrylate; MMA, methylmethacrylate; PLR, powder-to-liquid ratio; PMMA, poly(methylmethacrylate); $\mathrm{SBF}$, simulated body fluid; $\sigma_{\mathrm{c}}$, yield compressive stress; SCA, blend of starch/cellulose acetate; $t_{\mathrm{d}}$, dough time; $T_{\max }$, maximum polymerization temperature; $t_{\mathrm{s}}$, setting time; UTS, ultimate tensile strength; $W U$, water uptake

*Corresponding author. Tel.: + 35134915622900 ; fax: + 35134915644853 .

E-mail address: 1fboesel@dep.uminho.pt (L.F. Boesel).
} 


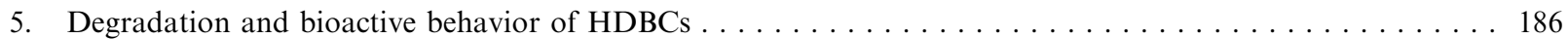

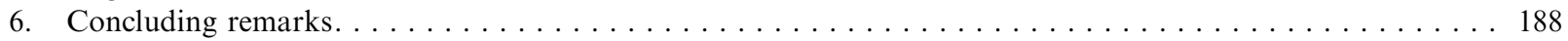

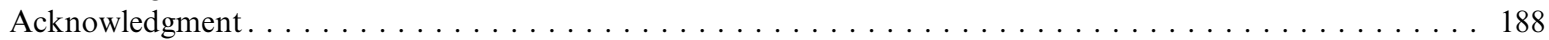

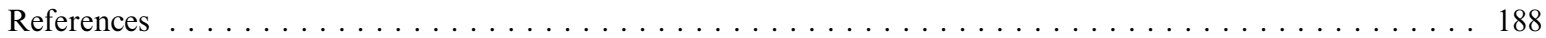

\section{Introduction}

Acrylic bone cements were used in the late 50s for fixing hip prostheses during total hip arthroplasty [1]. They were composed of cold-polymerized poly(methylmethacrylate) (PMMA), which reached the final setting in situ and could thus serve as an elastic buffer, maintaining the prosthesis in place and transferring the load from the prosthesis to the bone.

Since then, little has changed in the composition of commercially available formulations. All of them are composed of two phases. The solid is composed of PMMA or copolymers thereof, initiator (benzoyl peroxide, BPO) and an opacifier $\left(\mathrm{ZrO}_{2}\right.$ or $\left.\mathrm{BaSO}_{4}\right)$; the liquid component is methylmethacrylate (MMA) monomer or a mixture with butyl methacrylate, an activator (dimethyl- $p$-toluidine, DMT) and a stabilizer to avoid premature polymerization. Colorant (chlorophyllin) and antibiotics may also be present in some formulations. These cements are one of the most traditional classes of biomaterials in use, and are simultaneously, the object of intensive research in universities and companies worldwide.

Bone cements are well suited to their function and have an excellent performance record. Despite several modifications, proposed as alternatives to the original formulations, none have been successfully introduced in the market. Therefore, acrylic bone cements are still the gold standard in arthroplasty.

This does not mean bone cements are free of drawbacks that limit their performance. On the contrary, problems such as thermal or chemical necrosis of the bone, high porosity, low interfacial strength between cement and bone and between cement and prosthesis, residual shrinkage stresses, infection and inflammation, among other complications, may occur [2,3], ultimately leading to aseptic loosening of the implant, the major cause of failure of hip arthroplasties $[2,4]$. Therefore, the search for modified acrylic formulations with improved mechanical and biological properties and better overall performance has been keen in recent years. The alterations to the conventional formulation have included fiber reinforcement (which was intended to improve mechanical properties, but presented serious drawbacks regarding handling), addition of bioactive fillers (which simultaneously improve mechanical properties and allow direct bonding to bone), replacement of radiopaque agents, toughened cements (by the addition of rubber particles or hydrophilic moieties), development of novel activators to replace DMT, partially degradable formulations (developed to improve the drug release profile of the cements, at the cost of compromised mechanical properties), crosslinked cements (developed to decrease chain mobility and improve mechanical properties) and two-solution formulations (as opposed to formulations with one solid and one liquid component). Accordingly, there are several review papers dealing with both the performance of commercially available cements and the properties of novel formulations.

Lewis [3] and Saha and Pal [5] reviewed all the data on mechanical properties of both commercial and experimental bone cements while Harper and Bonfield [6] focused on the tensile properties of commercially available cements. Kühn [7] presented a complete listing of all commercially available bone cements in Germany, comparing their composition, handling and mechanical properties (besides some other physical properties). Deb [2] and Serbetci and Hasirci [8] reviewed the latest developments in bone cement research, presenting the main properties, and advantages and disadvantages of the alternative formulations mentioned above. Harper [9] concentrated on bioactive cements, which are the major focus of attention in terms of novel formulations of bone cements. This set of publications also contains useful information about the basics of bone cements, and the reader is directed to them for more introductory information about the history, handling and mechanical properties, the behavior of the interfaces and the occurrence of infections, among other topics.

The present review covers the in vitro characterization of a novel class of acrylic bone cements, developed mainly in the last 5 years, which has not been reviewed previously. This formulation is a 
good example of multifunctional cements, that is, cements with modifications aimed to address several of the drawbacks at once. This is in contrast to the formulations mentioned above, which in general only try to address one or two of the problems encountered in acrylic bone cements.

\section{Composition and curing parameters of Hydrophilic, partially Degradable and Bioactive Cements (HDBCs)}

HDBCs represent a step forward in bone cement research and result from a careful examination of all the previously reported modifications. Their conception is based on a study of the major drawbacks of commercially available bone cements and of the modifications in composition that could overcome such drawbacks. Therefore, they are not "just another" alternative cement. Instead, they represent a novel concept in acrylic bone cements, in which several alternatives are combined in a synergistic way, achieving better results than any of them alone. The major modifications in this system are:

(a) hydrophilic behavior-as compared to hydrophobic cements, allowing better release of antibiotics and better stability through the "press-fitting" effect;

(b) gradient modulus - allowing a better transfer of load to the bone while still maintaining a high modulus near the prosthesis-cement interface;

(c) degradability - provided by the incorporation of degradable polymers and enhanced by hydrophilic character;

(d) bioactivity - provided by the incorporation of bioactive fillers and enhanced by both hydrophilic character and degradability.

These four characteristics, if adequately coupled, can simultaneously improve the cement performance and avoid the drawbacks of each individual modification, as discussed earlier.

HDBCs contain a hydrophilic monomer in the liquid component, partially replacing MMA in order to modify the mechanical and swelling properties of the system. The hydrophilic monomer used initially - acrylic acid (AA) - was later replaced by 2-hydroxyethyl methacrylate (HEMA) for the reasons explained in Section 5. These cements also incorporate starch-based polymers that can degrade in the body and that have already been studied for a range of biomedical applications.
Most of the work has so far been concentrated on blends of starch with cellulose acetate (SCA), because of their good mechanical properties and handling behavior. Recently, pure gelatinized starch or starch containing methacrylic groups have been also used.

The curing parameters were shown to be strongly affected by the composition. As the hydrophilic monomers (AA, HEMA) have an enthalpy of polymerization higher than MMA, they tend to increase maximum polymerization temperature $\left(T_{\max }\right)$. In fact, a lower powder-to-liquid monomer ratio or $\mathrm{MMA} / \mathrm{AA}$ ratio leads to higher $T_{\max }$ $[10,11]$, while setting time $\left(t_{\mathrm{s}}\right)$ is longer with a lower solid amount or higher MMA concentration [11]. A central composite design was employed to study the curing of HEMA-containing cements and the effects of activator, inhibitor and initiator of polymerization [12]. It was concluded that lower levels of BPO were needed for obtaining long $t_{\mathrm{s}}$, while for $T_{\max }$ it was important to have DMT opposed to the other two factors (i.e., low amounts of DMT and high amounts of BPO and hydroquinone, and viceversa). These results agree with those published by Oldfield and Yasuda [13], who stated that at high concentrations the amine used as the activator of BPO may have an inhibitory effect on the polymerization rate due to the formation of nitroxides.

A simple method to improve the curing parameters of acrylic bone cements is the addition of inert fillers such as ceramic or metal particles or fibers. For HDBC, however, the addition of glassy or ceramic fillers did not decrease $T_{\max }[10,14]$; on the other hand, $t_{\mathrm{s}}$ and dough time $\left(t_{\mathrm{d}}\right)$ were both increased with higher filler content. The lack of effect on $T_{\max }$ was attributed to SCA itself being inert with respect to the polymerization. In conventional cements PMMA plays an active role in the polymerization process, since monomer diffuses into the polymer particles and a matrix polymerization occurs [15]. In this case, replacement of PMMA by inert particles will decrease the enthalpy of dissolution and the enthalpy of matrix polymerization leading to an observable decrease in $T_{\max }$. In HDBC, the replacement of one inert polymer by another inert filler will have no appreciable effect on $T_{\max }$. Only small improvements in $t_{\mathrm{s}}$ and $t_{\mathrm{d}}$ were observed, owing to the higher density and smaller particle size of the fillers, leading to a lower total surface area to be wetted by the monomers. Typical values of curing parameters for HDBCs are shown in Table 1. 
Table 1

Typical curing parameters of HDBCs under two different conditions

\begin{tabular}{|c|c|c|c|c|c|}
\hline Formulation & $T_{\max }\left({ }^{\circ} \mathrm{C}\right)$ & $t_{\mathrm{s}}(\min )$ & $t_{\mathrm{d}}(\min )$ & Condition & Reference \\
\hline MMA/AA & $70-88$ & $4-5$ & 2 & ASTM, ISO ${ }^{\mathrm{a}}$ & {$[10,11]$} \\
\hline MMA/AA, with HA & $85-92$ & $6-8.5$ & $1.3-2.5$ & ASTM, ISO & {$[10]$} \\
\hline Commercial cements & $55-90$ & $4.5-13.5$ & $1.5-3.5$ & ASTM, ISO & [7] \\
\hline MMA/AA & 112 & 4 & 0.3 & Modified $^{\mathrm{b}}$ & {$[14]$} \\
\hline MMA/AA, with bioactive glass & $114-116$ & $3-4$ & $0.4-1.1$ & Modified & {$[14]$} \\
\hline HEMA & $77-96$ & $1-4$ & - & Modified & {$[12]$} \\
\hline Palacos ${ }^{\circledR} \mathrm{R}$ & 107 & 7 & - & Modified & {$[14]$} \\
\hline
\end{tabular}

${ }^{a}$ According to the conditions in ASTM [16] and ISO [17] standards.

${ }^{\mathrm{b}}$ Modified conditions: storage at $T=4{ }^{\circ} \mathrm{C}$, testing at $T=37^{\circ} \mathrm{C}$ [14].

\section{Water uptake and press-fitting effect in confined environments}

The desired hydrophilic character is provided by a hydrogel-forming monomer. In order to keep the formulation close to the original one, these monomers were also acrylics, such as AA $[10,11,18]$ or HEMA [19-21]. They could be incorporated in the formulation either as a co-monomer together with MMA or as the only monomer. Because of the requirement of good mechanical properties both in dry and wet states, however, mixtures of MMA with one of the hydrophilic monomers have been preferred. HEMA is less hydrophilic than AA; therefore, similar levels of water uptake $(W U)$ were achieved when HEMA was present in much higher amounts than AA [22]. In either case, $W U$ increased with increasing amount of the hydrophilic monomer in the formulation, and could be adjusted to values ranging from 20 to $65 \mathrm{wt} \% \quad[10,11,14,18]$. AA additionally made $W U \mathrm{pH}$ dependent to the cements, the highest uptake occurring in general at $\mathrm{pH}$ 7. If a copolymer was formed (MMA/AA or MMA/HEMA), the water sorption followed fickian behavior, while the behavior was closer to Case II sorption if AA alone was used [18]. Fickian diffusion is more favorable for the intended applications, since in this case the polymer will contain a more homogeneous distribution of water in the bulk. This behavior is similar to that of commercially available bone cements, which have a reported diffusion coefficient of $2.3 \times 10^{-8} \mathrm{~cm}^{2} / \mathrm{s}$ [23], as compared to $1.8 \times 10^{-8} \mathrm{~cm}^{2} / \mathrm{s}$ for HDBC (unpublished data). However, because of the very low $W U$ of commercial formulations (usually lower than $3 \mathrm{wt} \%[23,24]$ ), the data for diffusion coefficients has only minor relevance, while they are important in determining the evolution of several properties of HDBCs, as will be shown later.

In general, experiments for $W U$ are performed in a free state, where the specimen, immersed in buffer solution or saline fluid sorbs water and is able to swell freely. Fig. 1 shows that the evolution of weight and volume of a specimen allowed to swell freely follows similar profiles. Although such tests are easier to perform and can give indications of the hydrophilic character of materials, they do not represent accurately the in vivo situation, in which the cement is constrained by the prosthesis and the bone. This situation will not only restrict $W U$, because of the impossibility of swelling, but will also create a "swelling pressure" effect [19]: i.e. the cement will exert a pressure against the walls (bone and prosthesis) which restricts the swelling of the material.

When the uptake of water occurs in conditions simulating those found in vivo, no swelling is allowed and the equilibrium water content is greatly reduced, as shown in Fig. 1b. The consequent pressure exerted by the cement evolves linearly with time and may grow at a rate of up to $110 \mathrm{kPa} / \mathrm{h}$ (Fig. 1a). This behavior could be adjusted by several parameters, such as the monomer ratio, presence of filler, crosslinking, etc. [19]. In contrast, for conventional cements, due to their very low $W U$, no differences are seen between free and constrained swelling; and consequently, no swelling pressure is observed.

The hydrophilic behavior and consequent swelling pressure were shown to increase the stability of the cement in early stages of implantation. When subjected to push-out tests (extraction of a cylindrical specimen from metal capsules), commercial cement performed much worse than the HDBC formulation (Table 2) $[19,25]$. The increased push-out 

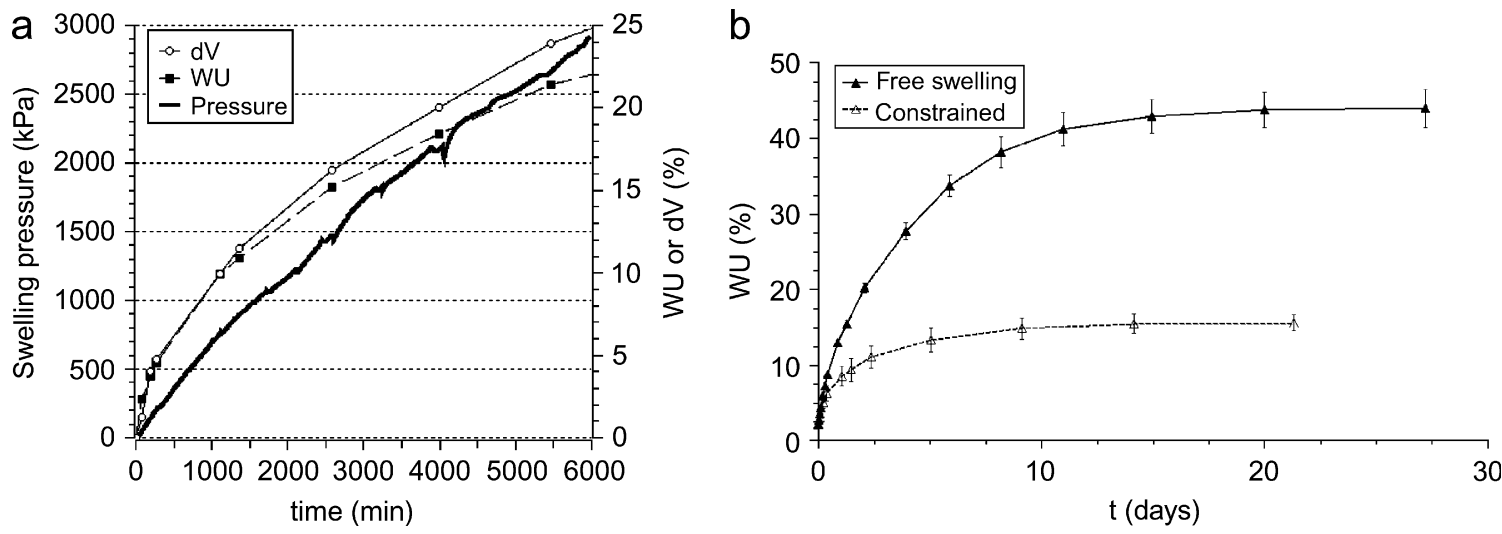

Fig. 1. (a) Evolution of water uptake $(W U)$ and swelling $(\mathrm{d} V)$ in free environments; evolution of swelling pressure with immersion time in confined environments. (b) Comparison of the water uptake $(W U)$ of one HDBC formulation when immersed in free and confined environments [19].

Table 2

Typical mechanical and interfacial properties of HDBCs

\begin{tabular}{|c|c|c|c|c|c|c|}
\hline Formulation & $E_{\mathrm{c}}(\mathrm{GPa})$ & $\sigma_{\mathrm{c}}(\mathrm{MPa})$ & $E_{\mathrm{t}}(\mathrm{GPa})$ & UTS (MPa) & Push-out force $(\mathrm{kN})$ & Reference \\
\hline MMA/AA & $1.3-2.1$ & $45-98$ & $2.5-3.8$ & $13-29$ & & {$[10,11,18]$} \\
\hline MMA/HEMA & 1.6 & 64 & 1.3 & 30 & 1.3 & {$[19,27]$} \\
\hline MMA/AA, with HA & $1.8-2.3$ & $56-88$ & $3.2-5.6$ & $6.4-17$ & & {$[10]$} \\
\hline MMA/AA, with bioactive glass & $2.0-4.0$ & $58-100$ & 2.1 & 30 & & [14] \\
\hline MMA/HEMA, with bioactive glass & & & 2.4 & 28 & 1.5 & {$[19,27]$} \\
\hline MMA/HEMA, with clay & & & 1.4 & 28 & & {$[27]$} \\
\hline Commercially available cements & $1.7-3.2$ & $68-114$ & $1.6-4.1$ & $24-51$ & & {$[3,6,7]$} \\
\hline Palacos ${ }^{\mathrm{R}} \mathrm{R}$ & 2.8 & 93 & & & 0.1 & {$[14,19]$} \\
\hline
\end{tabular}

force was attributed not only to the press-fitting effect but also to the swelling of the HDBC against any interstices present in the constrained wall, creating an additional mechanical interlocking. The improved performance of HDBC in push-out tests is an indication that the interface would be stronger in the first days after implantation: the press-fitting effect would be complementary to mechanical interlocking and chemical adhesion and would decrease the risk of micro-motion at the cement-bone interface. Another mechanism (bioactivity) would be more relevant in the long term, as shown below. These phenomena will also contribute to release of the residual shrinkage stresses, which always remain at the stemcement interface [26] and facilitate the failure of the cement.

\section{Mechanical properties of HDBCs}

The mechanical properties of HDBCs were studied under static, quasistatic and dynamic conditions; in tensile, compressive and bending modes; in dry, partially swelled and fully swelled states; in free and confined conditions [10,11, $14,18,19,28,29]$. This wide range of tests was designed to cover the situations the material might face in vivo.

In general, the compressive strength of MMA/ AA cements increased with increasing solid content as the solid content was varied from 30 to $60 \mathrm{wt} \%$ $[10,18]$. On the other hand, compressive modulus $\left(E_{\mathrm{c}}\right)$ did not follow a clear trend. A design of experiments was applied to study the effect of parameters such as the amount of solid, particle size, mole ratio of the monomers, and others on the mechanical properties. The composition of the monomer mixture was found to be the most important factor determining the compressive properties of HDBCs [11]. In tensile tests, similar behavior was seen: an increase in ultimate tensile strength (UTS) with higher solid content, but no clear influence on the modulus $[10,18]$. By adjusting the composition of the formulation, properties 
better than required by the standards could be achieved.

The decrease in wet mechanical properties of HDBCs is one of the major drawbacks as compared to the standard formulations. Bone cements are required to maintain good mechanical properties after long periods of implantation. Commercially available cements, due to their hydrophobic behavior, show only a moderate decrease in compressive and bending properties after 4 weeks in water at $37^{\circ} \mathrm{C}$ [7], and therefore comply well with such requirements. HDBCs, on the other hand, may show up to $88 \%$ decrease in yield compressive stress after only 1 week of immersion in a condition allowing free swelling [11]. The most important factor that contributes to this decrease in mechanical properties is the hydrophilic character of the material, controlled by the mole ratio of monomers [11]. Fig. 2a shows this effect; clearly if high wet mechanical properties were the only property to consider, higher amounts of MMA should be used. However, this would decrease the hydrophilicity of the formulation and all the advantages arising from this characteristic. An intermediate value of 2.0 was considered a good compromise between these antagonistic requirements. A somewhat different picture was observed when in vivo conditions were simulated (Fig. 2b) by restricting the amount of sorbed water. Here, HDBC formulations were able to retain approximately $50 \%$ of the initial compressive strength after taking up $10 \mathrm{wt} \%$ of water [30], a value that could better represent the in vivo $W U[19]$.

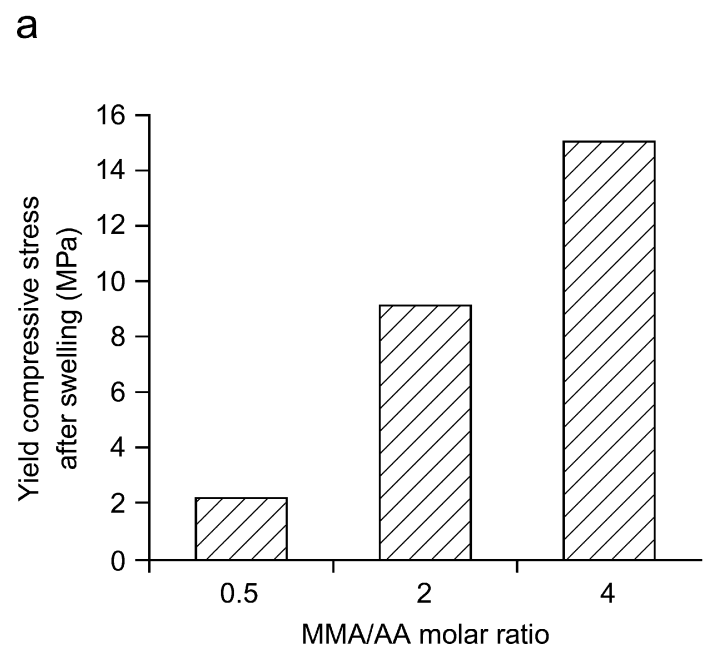

Tensile modulus and strength decreased after 7 days of water uptake; however, ductility and energyto-break increased steadily up to 3 days immersion [28]. Even after 100 days of immersion, energy to break was twice that of the dry specimen [28]. The failure mode changed from a brittle one, with rapid failure after crack nucleation to a ductile one, with a rough fracture surface [11]. This change in behavior is due to the plasticization induced by water, which produces a cement with low modulus at the interface with the bone, where the cement will take up water. The opposite interface (with the stem) will be initially dry, and such a situation will turn the HDBC into a sort of "gradient modulus" cement. The high modulus in the inner part of the mantle will contribute to maintaining the stiffness necessary to keep the prosthesis in place under a load. The low modulus at the interface with the bone will decrease the local contact stresses usual with commercially available cements, which cause bone resorption and, ultimately, loosening of the implant [31]. This behavior is also an advantage over simple low modulus cements, which have been introduced to minimize the inadequate load distribution of conventional formulations and high contact stresses between cement and bone. However, low modulus cements exhibit shorter fatigue lives [32] and high creep rates [33], leading to failure of the mantle and subsidence of the prosthesis.

Creep of HDBC was also influenced by the composition: the higher the amount of hydrophobic monomer, the lower the creep rates in wet conditions [11]; the more hydrophobic formulations also

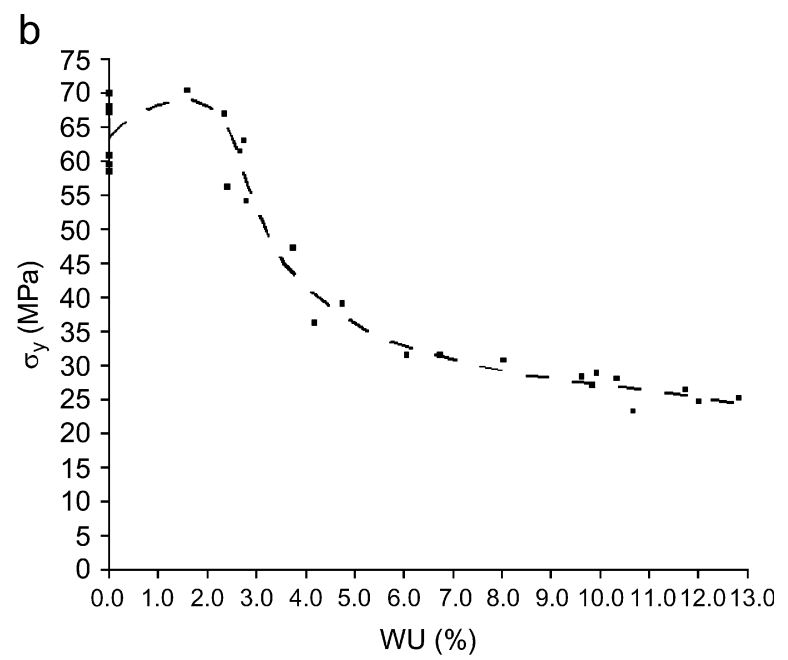

Fig. 2. Influence of the mole ratio of the monomer mixture MMA/AA (a) and of the level of water uptake (b) on the wet mechanical properties of HDBC [11]. 
showed smaller residual (permanent) deformation in creep/recovery tests. In free swelling, HDBCs showed higher creep rates and permanent deformation than commercially available cements, for the reasons discussed in the previous paragraph. Although creep tests under constrained swelling conditions have not been performed, the different behaviors of HDBC with more hydrophobic or more hydrophilic character may be taken as an indication that in this situation HDBCs would perform better. Moreover, the formation of an apatite-like layer due to the addition of glass particles (see Section 5) increased the creep resistance under bending, showing the reinforcing effect of such a layer [29].

These results indicate the strong influence of $W U$ on the mechanical performance of the developed cements and the need for a correct adjustment of the hydrophilicity of the formulation in order to maintain sufficient mechanical properties after implantation. While important parameters such as modulus and compressive strength decrease as a consequence of water sorption, the cements become tougher and less prone to fragile fracture. A balance between these antagonistic effects will be essential to achieve successful long-term performance without rendering the material too hydrophobic. To some extent, the addition of inorganic fillers may be used to compensate for the decrease in stiffness and strength without compromising the hydrophilic character.

Bioactive fillers also had an effect on quasistatic mechanical properties in the dry state. HA, sintered or not, increased compressive and tensile properties (Table 2) [10]. The higher the amount of HA, the higher the moduli when the solid content was as much to $50 \mathrm{wt} \%$. Regarding UTS, sintered HA gave, in general, better results than the non-sintered one, while there was no clear trend for compressive strength. When the filler was a bioactive glass, both compressive yield strength $\left(\sigma_{\mathrm{c}}\right)$ and modulus increased monotonically as loading increased up to $30 \mathrm{wt} \%$ [14]. With either filler, the mechanical properties are severely affected by $W U$, once water can be easily absorbed at the filler-matrix interfaces [27]. To solve this issue, organophilic clay was added instead. Such fillers may be exfoliated (ultimately achieving nanoscale dispersion) and have a much better interaction with the polymer. As a result, both compressive and tensile moduli after swelling increased by about $30 \%$ with the addition of only $2.4 \mathrm{wt} \%$ of clay [27].

\section{Degradation and bioactive behavior of HDBCs}

The degradable character of HDBCs is provided by corn-starch-based polymers, which can degrade in the body by hydrolysis. This process is catalyzed by $\alpha$-amylase, an enzyme present at low concentrations in human serum. The polymer used for the majority of tests was a blend of starch with cellulose acetate (SCA), which has already been studied for a range of biomedical applications, such as scaffolds for tissue engineering [34,35], systems for drug delivery [36] and hydrogels [37,38], and has also been proposed for bone replacement and regeneration applications [39]. While SCA itself degrades under the action of $\alpha$-amylase, the presence of $35-40 \%$ of acrylic polymers in the cement formulation hinders the access of the enzyme to the starch particles, resulting in almost no degradation [20]. To overcome this problem, thermostable $\alpha$-amylase was incorporated into the cement. This enzyme withstood the polymerization temperature and caused visible degradation of the cement [20,22]. The amount of reducing sugars (products of starch degradation) in solution increased steadily with degradation time or enzyme concentration, and this degradation corresponded to the formation of a connected network of pores and voids (Fig. 3), which was not present in the material without the enzyme.

More recently, pure gelatinized starch or starch modified with methacrylic side groups has also been used as the solid component of HDBCs [40]. The main rationale for their use was an increase in the

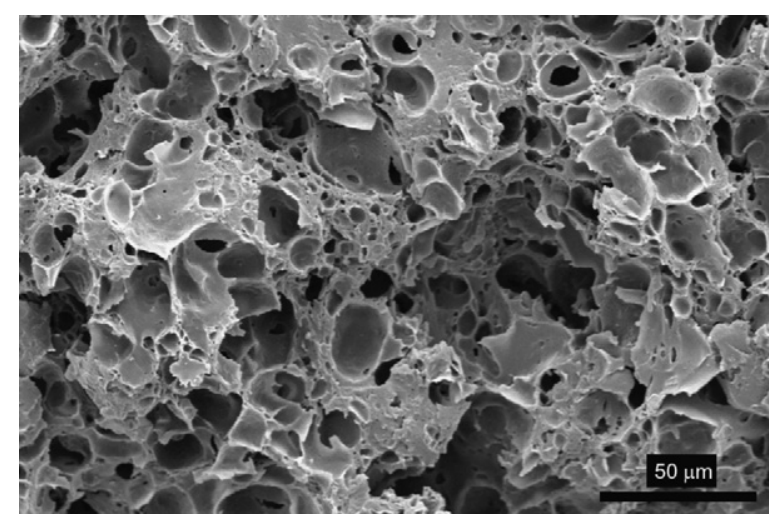

Fig. 3. Morphology of the interior of a specimen after enzymatic degradation. The pores were formed in the volume previously occupied by the degradable polymer [20]. Specimen containing SCA and HEMA/ $\alpha$-amylase; powder-to-liquid ratio $(\mathrm{PLR})=$ 1.86 . 
total amount of starch in the formulation, since a minimum of $31.2 \mathrm{vol} \%$ of the dispersed phase is required to achieve the percolation threshold [41] and, therefore, to guarantee full accessibility of the starch to the enzyme present in circulating fluid. In this case, there would be no need to add thermostable $\alpha$-amylase to the formulation, since the enzyme from the fluid could diffuse through the polymer more easily. Formulations containing methacrylated starch (with a degree of substitution of 1.76) showed, after 4 weeks, four times as much degradation as similar formulations with SCA $[20,40]$, without added enzyme.

This behavior is basically restricted to HDBC systems, since commercially available cements and most other experimental formulations are inert. A few formulations contain hydrolitically degradable polymers [42,43]. HDBCs, however, have the advantage of degradation being independent of $W U$. Therefore, by playing with the composition of the solid component or with the amount of incorporated enzyme, one may adjust the degradation rate and extent without large variations in the hydrophilic character of the formulation. While degradation (with the consequent porosity formation) per se is deleterious to the mechanical properties of the cements [22], its real advantage is related to bioactive behavior, which is discussed next.

Regarding bioactivity, two kinds of fillers were incorporated into the cements: HA $[10,14]$ and glasses $[14,21,22]$. It was found that AA inhibits the formation of a calcium phosphate layer [14], unless a very reactive glass is used [22] or if the simulated body fluid (SBF) solution is renewed periodically [10]. That was the main reason for replacement of this monomer by HEMA. HEMA did not present this inhibitory effect, and by choosing appropriate glasses, a dense layer of calcium phosphate could be formed in less than 1 week (Fig. 4) [21]. Moreover, the behavior of glasses was found to be better than that of HA, in accordance with other reports in the literature $[44,45]$.

Commercially available cements do not bond to bone, and this lack of a strong interaction is one of the main reasons for the aseptic loosening of the implant. Due to this fact, intensive research has been devoted to the development of novel formulations that bond strongly to bone. Bioactive cements $[2,8,9]$ were formulated with HA, glasses or glassceramics, achieving good mechanical properties and strong bonding to bone. However, they were all

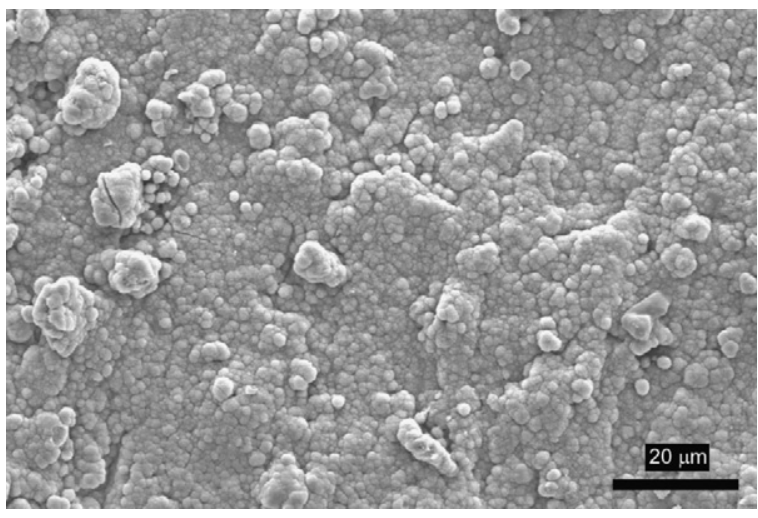

Fig. 4. Surface morphology of a specimen of HDBC after immersion in SBF. A dense layer of calcium phosphate precipitated on the surface [21]. Specimen containing SCA/ bioactive glass ( $50 / 50$ by weight in the solid component) and HEMA; PLR $=1.86$.

based on inert, hydrophobic matrices, leading to a need to expose of particles on the surface of the cement. Accordingly, the bonding occurred only at the interface. HDBCs, in contrast, are hydrophilic and partially degradable. Bone, therefore, could grow not only at the interface, but could also infiltrate throughout the material, occupying the pores generated during degradation. Ultimately, this would lead to a kind of "bone-reinforced cement", and the amount of the cement-bone interface should be much greater than in other systems. Both effects would compensate for the reduced mechanical properties of HDBC (due to $W U$ ) and generate a bonding to bone much stronger than with other formulations.

Bioactivity and enzymatic degradation tests were performed simultaneously in vitro, to check the aforementioned hypothesis. Calcium phosphate precipitates were detected inside the pores generated during degradation [20,46]. This effect is displayed in Fig. 5, where a pore on the surface of the specimen is covered by a layer of calcium phosphate agglomerates. The agglomerates were visible after the first week of immersion in SBF. The walls of pores close to the surface were completely covered by calcium phosphate layers, while in inner pores the spreading was less extensive. Nonetheless, such results demonstrate the potential of HDBC to induce the growth of bone in the bulk of the cement mantle. The growing of calcium phosphate layer on the surface and in the pores had also positive effects on mechanical properties as discussed above. 


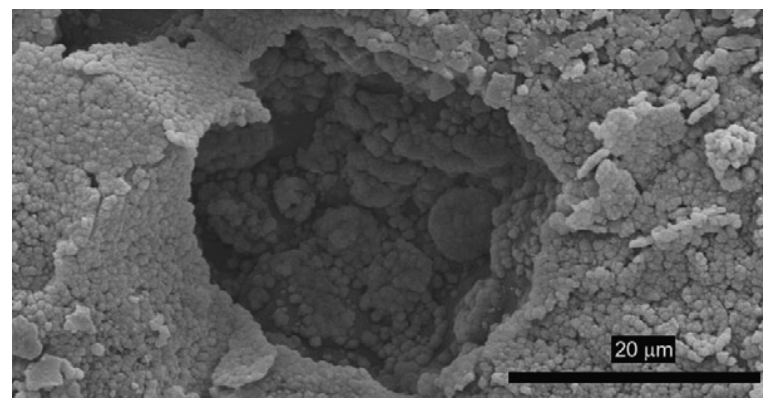

Fig. 5. Formation of calcium phosphate precipitates on the walls of a surface pore, formed during the degradation of starch catalyzed by $\alpha$-amylase [20]. Specimen containing SCA/bioactive glass $(50 / 50$ by weight in the solid component) and HEMA $/ \alpha$ amylase; PLR $=1.86$.

\section{Concluding remarks}

The data developed in the last 5 years on HDBCs have shown this system is a potential alternative to replace commercially available cements in arthroplasties and as bone filling materials. HDBCs are not simple "one more" alternative to the conventional bone cements. After analyzing the drawbacks of conventional bone cements and the advantages and disadvantages of the several alternatives already developed, HDBCs were designed combining several modifications in one system, creating a system able to compensate for the shortcomings of each individual modification. These cements are intended, in vivo, to sorb water immediately after implantation. The sorption would trigger the swelling pressure and press-fitting effect, improving the stability of the interface; meanwhile, the cement would gradually change from a "normal" to a "gradient" modulus cement. Water would also initiate the degradation of starch, catalyzed by the incorporated thermostable $\alpha$-amylase, while the bioactive fillers would favor the growth of new bone first at the interface and, as degradation progresses, inside the pores of the degraded cement. Thus, the final situation would be that of a low modulus cement reinforced by bone, with a very large, strong cement-bone interface, thus ensuring the required strength and toughness for keeping the prosthesis functional.

The future of bone cement research, in accordance with current trends in biomaterials, rests on multifunctional systems that are able to interact with body tissues. In this way, much better overall performance may be achieved as compared with inert systems such as the commercially available cements. As most bone cement research has concentrated on increasing the cement-bone interaction (bioactive cements), other important characteristics have been neglected: compatibility with body fluids, penetration of bone inside the cement mantle, better distribution of the load from the prosthesis to the bone. Only multifunctional cements may be able to address all these issues simultaneously. Among this novel class of polymeric cements, HDBCs have been shown to be one of the best alternatives and whose development is more advanced. Their extensive in vitro characterization reviewed here authorizes further steps into biological tests and in vivo experiments, which would confirm whether the cement has adequate properties for the intended applications.

\section{Acknowledgment}

L.F. Boesel acknowledges a Ph.D. grant from Fundação Coordenação de Aperfeiçoamento de Pessoal do Ensino Superior (CAPES), Brasília, Brazil.

\section{References}

[1] Charnley J. Anchorage of the femoral head prosthesis to the shaft of the femur. J Bone Joint Surg 1960;42B:28-30.

[2] Deb S. A review of improvements in acrylic bone cements. J Biomater Appl 1999;14:16-48.

[3] Lewis G. Properties of acrylic bone cements: state of the art review. J Biomed Mater Res: Appl Biomater 1997;38: 155-82.

[4] The Swedish National Hip Arthroplasty Register. Annual report 2003. Göteborg, Sweden: Sahlgrenska University Hospital; 2004.

[5] Saha S, Pal S. Mechanical properties of bone cement: a review. J Biomed Mater Res 1984;18:435-62.

[6] Harper EJ, Bonfield W. Tensile characteristics of ten commercial acrylic bone cements. J Biomed Mater Res: Appl Biomater 2000;53:605-16.

[7] Kühn KD. Bone cements: up to date comparison of physical and chemical properties of commercial materials. Berlin: Springer; 2000.

[8] Serbetci K, Hasirci N. Recent developments in bone cements. In: Yaszemski MJ, et al., editors. Biomaterials in orthopedics. New York: Marcel Dekker; 2004. p. 241-86.

[9] Harper EJ. Bioactive bone cements. P I Mech Eng H 1998; 212:113-20.

[10] Espígares I, Elvira C, Mano JF, Vázquez B, San Román J, Reis RL. New partially degradable and bioactive acrylic bone cements based on starch blends and ceramic fillers. Biomaterials 2003;23:1883-95.

[11] Boesel LF, Mano JF, Reis RL. Optimization of the formulation and mechanical properties of starch based 
partially degradable bone cements. J Mater Sci: Mater Med 2004; 15:73-83.

[12] Pinho ED, Boesel LF, Reis RL. Optimization of the curing properties of hydrophilic partially degradable bioactive cements using statistical tools. In: Proceedings of the annual meeting of the society for biomaterials, vol. 30. Memphis; 2005. p. 435.

[13] Oldfield F, Yasuda H. ESR study of MMA polymerization by a peroxide/amine system: bone cement formation. J Biomed Mater Res 1999;44:436-45.

[14] Boesel LF, Fernandes MHV, Reis RL. The behavior of novel hydrophilic composite bone cements in simulated body fluids. J Biomed Mater Res B 2004;70B: 368-77.

[15] Lautenschlager EP, Stupp SI, Keller JC. Structure and properties of acrylic bone cement. In: Ducheyne P, Hastings GW, editors. Functional behavior of orthopaedic materials, vol. II. Boca Raton: CRC; 1984. p. 87-119.

[16] ASTM. Standard specification for acrylic bone cement. Annual book of ASTM standards, v. 13.01, F451-99a. Philadelphia, USA; 2003. p. 103-10.

[17] ISO. Implants for surgery. Acrylic resin cements. ISO 5833. Geneva, Switzerland; 1992. p. 1-17.

[18] Pereira CS, Cunha AM, Reis RL, Vázquez B, San Román J. New starch-based thermoplastic hydrogels for use as bone cements or drug-delivery carriers. J Mater Sci: Mater Med 1998;9:825-33.

[19] Boesel LF, Reis RL. The effect of water uptake on the behaviour of hydrophilic cements in confined environments. Biomaterials 2006;27:5627-33.

[20] Boesel LF, Azevedo HS, Reis RL. Incorporation of aamylase enzyme and a bioactive filler into hydrophilic, partially degradable and bioactive cements (HDBCs) as a new approach to tailor their simultaneous degradation and bioactive behaviour. Biomacromolecules 2006;7: $2600-9$.

[21] Boesel LF, Cachinho SCP, Fernandes MHV, Reis RL. The in vitro bioactivity of two novel hydrophilic, degradable and bioactive cements. Acta Biomater 2007;3:175-82.

[22] Boesel LF, Reis RL. Hydrophilic matrices to be used as bioactive and degradable bone cements. J Mater Sci: Mater Med 2004;15:503-6.

[23] Deb S, Di Silvio L, Vazquez B, San Roman J. Water absorption characteristics and cytotoxic and biological evaluation of bone cements formulated with a novel activator. J Biomed Mater Res: Appl Biomater 1999;48: 719-25.

[24] Kjellson F, Brudeli B, McCarthy ID, Lidgren L. Water uptake and release from iodine-containing bone cement. J Biomed Mater Res A 2004;71A:292-8.

[25] Boesel LF, Reis RL. Increased interfacial strength in hydrophilic, partially degradable and bioactive cements due to water induced press fitting. In: Proceedings of the annual meeting of the society for biomaterials, vol. 30 . Memphis; 2005. p. 38.

[26] Roques A, Browne M, Taylor A, New A, Baker D. Quantitative measurement of the stresses induced during polymerisation of bone cement. Biomaterials 2004;25: 4415-24.

[27] Boesel LF, Pinho ED, Reis RL. Increase of the wet mechanical properties of hydrophilic, partially degradable and bioactive cements (HDBC) by employing different reinforcing methods. In: Proceedings of the Euromat, vol. 9. Prague; 2005. p. 47.

[28] Boesel LF, Reis RL. Novel partially degradable, hydrophylic bone cements incorporating starch: development and mechanical properties evolution. In: Proceedings of the annual meeting of the society for biomaterials, vol. 29. Reno; 2003. p. 474.

[29] Boesel LF, Mano JF, Fernandes MH, Cachinho S, Reis RL. The influence of bone-like apatite layers on the creep and dynamic mechanical behaviour of hydrophiic bone cements. In: Proceedings of the POLYCHAR World Forum on polymer applications and theory, vol. 12. Guimarães; 2004. p. 63 .

[30] Boesel LF. Development and characteriation of novel hydrophilic, partially degradable and bioactive acrylic bone cements (HDBCs). Ph.D. thesis, University of Minho; 2006.

[31] Yetlinker DN, Litsky AS. Viscoelastic behaviour of acrylic bone cements. Biomaterials 1998;19:1551-9.

[32] Harper EJ, Behiri JC, Bonfield W. Flexural and fatigue properties of a bone cement based upon polymethylmethacrylate and hydroxyapatite. J Mater Sci: Mater Med 1995;6:799-803.

[33] Arnold JC, Venditti NP. Effects of environment on the creep properties of a poly(ethylmethacrylate) based bone cement. J Mater Sci: Mater Med 2001;12:707-17.

[34] Pashkuleva I, Marques AP, Vaz F, Reis RL. Surface modification of starch based blends using potassium permanganate-nitric acid system and its effect on the adherence and proliferation of osteoblastic-like cells. J Mater Sci: Mater Med 2005;116:81-92.

[35] Gomes ME, Sikavitsas VI, Behravesh E, Reis RL, Mikos AG. Effect of flow perfusion on the osteogenic differentiation of bone marrow stromal cells cultured on starch-based three-dimensional scaffolds. J Biomed Mater Res A 2003; 67A:87-95.

[36] Silva GA, Costa FJ, Neves NM, Coutinho OP, Dias ACP, Reis RL. Entrapment ability and release profile of corticosteroids from starch-based microparticles. J Biomed Mater Res A 2005;73A:234-43.

[37] Elvira C, Mano JF, San Román J, Reis RL. Starch-based biodegradable hydrogels with potential biomedical applications as drug delivery systems. Biomaterials 2002;23: 1955-66.

[38] Baran ET, Mano JF, Reis RL. Starch-chitosan hydrogels prepared by reductive alkylation cross-linking. J Mater Sci: Mater Med 2004;15:759-65.

[39] Reis RL, Cunha AM, Allan PS, Bevis MJ. Structure development and control of injection-molded hydroxylapatite-reinforced starch/EVOH composites. Adv Polym Technol 1997;16:263-77.

[40] Mendes AC, Boesel LF, Reis RL. Effect of methacrylated starch in degradation properties of hydrophilic, partially degradable and bioactive cements (HDBC). In: Proceedings of the Marie Curie invents conference, vol. 3. Funchal; 2007. p. 1.

[41] Wool RP, Raghavan D, Wagner GC, Billieux S. Biodegradation dynamics of polymer-starch composites. J Appl Polym Sci 2000;77:1643-57.

[42] Frazier DD, Lathi VK, Gerhart TN, Hayes WC. Ex-vivo degradation of a poly(propylene glycol-fumarate) biodegradable particulate composite bone cement. J Biomed Mater Res A 1997;35:383-9. 
[43] Kuo SM, et al. Evaluating chitosan/ $\beta$-tricalcium phosphate/ poly(methyl methacrylate) cement composites as bonerepairing materials. J Appl Polym Sci 2003;89:3897-904.

[44] Shinzato S, Kobayashi M, Mousa WF, Kamimura M, Neo M, Kitamura Y, et al. Bioactive polymethyl methacrylatebased bone cement: comparison of glass beads, apatite- and wollastonite-containing glass-ceramics, and hydroxyapatite fillers on mechanical and biological properties. J Biomed Mater Res A 2000;51:258-72.
[45] Heikkilä JT, Aho AJ, Kangasniemi I, Yli-Urpo A Polymethylmethacrylate composites: disturbed bone formation at the surface of bioactive glass and hydroxyapatite. Biomaterials 1996;17:1755-60.

[46] Boesel LF, Azevedo HS, Reis RL. Novel hydrophilic, partially degradable and bioactive bone cements containing starch and a bioactive glass. In: Proceedings of the world biomaterials congress, vol. 7. Sydney; 2004 p. 742 . 